\title{
A Estratégia Gestão Autônoma da Medicação e a Inserção da (A)normalidade no Discurso da Cidadania
}

\author{
Vitória Rosa Cougo ${ }^{1}$ \\ ${ }^{1}$ Universidade Franciscana, RS, Brasil.
}

\author{
Marcos Adegas de Azambuja ${ }^{2}$ \\ ${ }^{2}$ Universidade Federal de Santa Maria, RS, Brasil.
}

\begin{abstract}
Resumo: Este trabalho tem por objetivo geral analisar as formas de compreensão e exercício da cidadania pelos sujeitos envolvidos com a implementação da estratégia Gestão Autônoma da Medicação (GAM) na macrorregião referente à $4^{\text {a }}$ Coordenadoria Regional de Saúde do Estado do RS. Como objetivos específicos pretende descrever as relações de saber e poder em torno dos medicamentos psiquiátricos que produzem o agrupamento de ativistas do Guia GAM, bem como pensar os modos pelos quais as anormalidades passaram a ocupar o discurso da normalidade no exercício político. Pela abordagem participante do tipo apoio, esta pesquisa reuniu gestores, profissionais, acadêmicos e usuários, em rodas de conversas para troca de experiências sobre estratégia GAM. Os encontros e o conteúdo dos guias GAM do usuário e do moderador foram analisados pela perspectiva arqueogenealógica de Michel Foucault. Discutiu-se o campo de forças estabelecido pelos pesquisadores na liberdade dos envolvidos para constituição de um sujeito crítico da saúde mental, assim como as práticas de conscientização, de fazer ouvir e falar para a formação do ativismo do usuário. Conclui-se que o exercício da cidadania na saúde mental passa pela afirmação da vulnerabilidade psiquiátrica do sujeito e da problematização da normalidade pela inserção da anormalidade neste campo discursivo.
\end{abstract}

Palavras-chave: GAM, Cidadania, Saúde Mental, Medicamentos Psiquiátricos.

\section{Autonomous Medication Management Strategy and the Introduction of (Ab)normalities in the Discourse of Citizenship}

\begin{abstract}
This paper aims to analyze the understandings and exercise of citizenship of subjects involved in the implementation of the GAM strategy in the macro-region of the 4th Regional Healthcare Coordination of Rio Grande do Sul. Its specific objectives are to describe the relations of knowledge and power around the psychiatric medications which the group of GAM activists is built upon, as well as to reflect on how abnormalities were introduced in the discourses of normality in the political exercise. Through a support participant observation, this study gathered managers, professionals, scholars and users in conversation circles to exchange experiences on GAM strategy. Both the meetings and the content of GAM user guide and moderator guide were analyzed based on the archeogenealogical perspective of Michel Foucault. The force field established by researchers considering the individuals' freedom to constitute a critical subject of mental health was discussed in this study, as well as the awareness practices of listening and speaking in building user activism. It can be concluded that the exercise of citizenship in mental health involves stating the psychiatric vulnerability of the subject and problematizing the principles of normality by introducing the abnormality in this discursive field.
\end{abstract}

Keywords: GAM, Citizenship, Mental Health, Psychiatric Medications. 


\title{
La Estrategia Gestión Autónoma de la Medicación y la Inserción de la (A)normalidad en el Discurso de la Ciudadanía
}

\begin{abstract}
Resumen: Este trabajo tiene como objetivo analizar las formas de comprensión y practica de la ciudadanía por parte de los sujetos involucrados en la implementación de la estrategia Gestión Autónoma de la Medicación (GAM) en la macro-región de la 4ª Coordinación Regional del Departamento de Salud del Estado de Rio Grande do Sul. Como objetivos específicos pretende describir las relaciones de saber y poder en torno a los medicamentos psiquiátricos que producen la agrupación de activistas de la Guía GAM, así como pensar los modos por los cuales las anormalidades pasaron a ocupar el discurso de la normalidad en el ejercicio político. Por el abordaje participante del tipo apoyo, esta investigación reunió a gestores, profesionales, académicos y usuarios, en ruedas de conversaciones para intercambio de experiencias sobre estrategia GAM. Los encuentros y el contenido de las guías GAM del usuario y del moderador fueron analizados por la perspectiva arqueogenalógica de Michel Foucault. Se discutió el campo de fuerzas establecido por los investigadores en la libertad de los involucrados para la constitución de un sujeto crítico de la salud mental, así como las prácticas de concientización, de hacer oír y hablar para la formación del activismo del usuario. Se concluye que el ejercicio de la ciudadanía en la salud mental pasa por la afirmación de la vulnerabilidad psiquiátrica del sujeto y de la problematización de la normalidad por la inserción de la anormalidad en este campo discursivo.
\end{abstract}

Palabras clave: GAM, La Ciudadanía, Salud Mental, Medicamentos Psiquiátricos.

\section{Introdução}

Este artigo é fruto da experiência de pesquisa multicêntrica denominada (título retirado para evitar identificação dos autores), que acompanha o percurso de efetivação do Guia da Gestão Autônoma da Medicação (GAM) nos serviços de saúde de três macrorregiões do Rio Grande do Sul. O Guia GAM surgiu na província de Quebec, no Canadá, e foi criado por usuários com o intuito de ser uma ferramenta de cuidado em saúde mental para diminuir e, em alguns casos, eliminar o uso de medicamentos psicotrópicos nos tratamentos.

Com sua chegada ao Brasil, em 2009, o GAM foi traduzido e adaptado com a finalidade de pensar o uso dos medicamentos como um meio para se alcançar relações mais horizontais entre gestores, trabalhadores e usuários dos serviços de saúde mental, de informar sobre os direitos desses usuários, bem como estimular o pensamento crítico e proporcionar um espaço de protagonismo, autonomia e cogestão frente ao tratamento de psicofármacos. Após sua disseminação e implementação, o GAM foi incorporado como política pública no Rio Grande do Sul pela Secretaria Estadual de Saúde (SES) por meio do Departamento de Ações de Saúde, em 2013.
No Canadá a GAM surgiu por diligência de movimentos sociais e iniciativa popular, sem ligação direta com políticas de Estado. Já no Brasil, ela surgiu pelo interesse de instituições, como universidades e serviços públicos de saúde. Assim, o Guia GAM é consequência e complemento de um tipo de cuidado em saúde mental que vem sendo produzido no contexto brasileiro desde a Reforma Psiquiátrica. Esse cuidado é composto por práticas que formam um circuito estratégico que possibilita a produção de um sujeito da saúde mental que possui um papel político fundamental, não se subjetivando apenas como paciente, usuário ou doente, mas também como pessoa e cidadão, que possui e luta por seus direitos e deveres.

Com a Constituição de 1988, no Brasil, as questões que dizem respeito à saúde passam a estar muito atreladas ao campo da cidadania. Junto a isso, o Sistema Único de Saúde (SUS) surge com base em princípios políticos de solidariedade social, garantia da participação da população, universalidade ao acesso em saúde, equidade e integralidade da atenção. A Saúde Mental também entra nesta esteira política (Reforma Psiquiátrica - Lei $\mathrm{n}^{\circ}$ 10.216) com os movimentos da luta antimanicomial e da desinstitucionalização (Amarante, 2000, Basaglia, 1985), questionando a lou- 
cura e a diferença, rompendo com estereótipos e discriminações para construir sujeitos cidadãos.

O surgimento de práticas não tradicionais no cuidado em saúde mental ocorre conjuntamente aos acontecimentos históricos que possibilitaram pensar o sujeito portador de doença mental de outras maneiras. Segundo Tenório (2002), a grande distinção dentre as constantes construções e rupturas que já foram exercidas na prática psiquiátrica no decorrer da história brasileira é que, na contemporaneidade, existe a tentativa de inserir o sujeito louco em uma identidade que possibilita que ele se posicione enquanto cidadão. A GAM é mais uma das ferramentas disruptivas ao modelo biomédico e psiquiátrico, organizando-se por um discurso que visa promover a cidadania. A inclusão, a tomada de direitos, o protagonismo e a integralidade do sujeito da saúde mental estão em consonância com o ideal de cuidado reivindicado.

É no campo de construção desta cidadania na saúde mental, que este artigo se propõe a pensar. Como os direitos dos usuários em saúde mental são estabelecidos mediante uma marca, uma diferença ou, talvez, mais precisamente, um déficit no sujeito em relação à sua condição psiquiátrica, parece-nos que o conceito de cidadania biológica cunhado por Rose (2013) pode auxiliar nossas análises:

projetos de cidadania que têm ligado suas concepções de cidadãos a crenças acerca da existência biológica dos seres humanos, como pessoas, como homens e mulheres, como famílias e linhagens, como comunidades, como populações e raças, e como espécies. E como outras dimensões de cidadania, a cidadania biológica está sofrendo transformação e está, ela mesma, reassumindo seu território juntamente com as dimensões nacional, local e transnacional (p. 190).

Não podemos compreender este investimento na vida no que tange ao biológico somente em termos eugênicos. Diferentemente dos projetos de cidadania dos séculos XIX e XX, que produziam cidadãos fiéis à sua nacionalidade em termos biológicos e raciais, na contemporaneidade os laços entre biologia e dignidade humana produzem, dentre suas várias nuances, aquela que é mais significativa, no que concerne não na eliminação dos defeitos humanos, mas no interesse em investir sobre essas vidas, tanto do Estado, quanto do mercado. Acompanhamos a formação de sujei- tos que lutam pela inserção social, reconhecimento de direitos e participação política, enquanto sujeitos portadores de um déficit biológico, criando-se novos modos de viver em sociedade. Assim, atualmente, pode-se pensar o papel da biologia na dignidade humana em práticas de aborto seletivo, implantação genética, seleção de embrião; nas responsabilidades biológicas dos cidadãos inseridos no campo da saúde e educação sanitária; na importância da corporeidade para as práticas identitárias (negros, índios, homo/bi/ transexuais...), bem como nas tecnologias biomédicas que intervêm na alteração do corpo; por fim, em genes de grupos de cidadãos que são objeto de inovação biotecnológica (Rose, 2013).

Percebe-se historicamente que o fato biológico fundamental de que o ser humano constitui uma espécie humana adentra a esfera política, ou seja, a vida passa a ser governada, seja por estratégias disciplinares sobre os corpos dos indivíduos, seja por procedimentos biopolíticos sobre o manejo da população, o que Michel Foucault denominou de biopoder. $\mathrm{O}$ argumento e análise sobre o conjunto de mecanismos pelo qual se estabelecem as características biológicas da espécie humana permitem a intervenção, ou melhor, a gestão da vida da população. Por meio de um aparato institucional, como hospitais, asilos, fábricas, escolas, exército, e de uma tecnologia científica, como instrumentos de levantamento de dados e seus resultados estatísticos, a vida da população ou do indivíduo torna-se objeto de investimento político e econômico, merecendo ser gerida (Foucault, 1988).

Considerando esta instigante mudança na forma como a cidadania vem sendo construída pelas autoridades, desde gestores e profissionais da saúde a usuários de diversos serviços, interessa-nos pensar essa biologização da política (Rose, 2013) no cruzamento com os campos da saúde mental e da psiquiatria. Assim, a estratégia GAM dá visibilidade à pluralidade de posições e escolhas em face da medicação e afirma o direito ao consentimento livre e esclarecido para utilização de psicofármacos e a necessidade da tomada compartilhada de decisões entre profissionais e usuários, tendo como pressuposto a ideia de que o tratamento em saúde mental é mais do que o uso de medicamentos e de que as pessoas são mais do que uma doença, não podendo ser reduzidas aos seus sintomas.

Neste contexto, interessa-nos analisar a GAM em seu caráter problematizador sobre os coletivos que se 
formam em torno de uma cidadania biológica - quer dizer, a possibilidade da formação de agrupamentos de usuários inseridos em estabelecimentos públicos de saúde ou saúde mental, vinculados ao SUS, a partir de classificações biomédicas, mais especificamente psiquiátricas, para defender seus direitos enquanto cidadãos. Esta biossocialidade (Rabinow, 1996), constitui uma ética de si e dos outros articulada às suas vulnerabilidades, sofrimento, risco e suscetibilidades somáticas. Nesse sentido, o guia GAM apresenta-se como um campo de análise frutífero para reflexões sobre como as pessoas envolvidas com as problemáticas da área da saúde mental contribuem para a construção de cidadanias que se agenciam em torno de diagnósticos psiquiátricos.

Em vista disso, o objetivo geral deste artigo é analisar as formas de compreensão e exercício da cidadania pelos sujeitos envolvidos na implementação da estratégia GAM em uma macrorregião do Rio Grande do Sul. Para isso, descreveremos as relações de saber e poder em torno dos medicamentos psiquiátricos que produzem o agrupamento de ativistas do Guia GAM, além de discutir como as anormalidades passaram a ocupar o discurso da normalidade a fim de exercer um papel político na sociedade.

\section{Percurso da pesquisa}

Esta pesquisa envolveu gestores, profissionais, acadêmicos e usuários que implementaram ou tiveram interesse em iniciar o uso da estratégia GAM nos serviços de saúde na macrorregião referente à $4^{\mathrm{a}}$ Coordenadoria Regional de Saúde do Estado do RS. Após a apresentação da proposta de pesquisa aos responsáveis pela área de saúde e saúde mental na região, usuários e moderadores foram convidados a participar de rodas de conversa sobre o Guia GAM. Estas rodas ocorreram em ambiente acadêmico, em uma sala de uma das universidades de Santa Maria/RS vinculada à pesquisa. Para este artigo, foram considerados os primeiros quatro encontros de um total de sete, com duração aproximada de três horas cada, gravados com o consentimento dos participantes. Todos os participantes estiveram cientes dos procedimentos da pesquisa e das gravações realizadas no ambiente descrito através da leitura do Termo de Consentimento Livre e Esclarecido (TCLE), aprovado pela Plataforma Brasil através do Certificado de Apresentação para Apreciação Ética (CAAE) de número 51818015.1.0000.5306. Os encontros foram bimestrais e contaram, em média, com 30 a 35 pessoas, entre profissionais, residentes, pesquisadores, estagiários e estudantes das seguintes áreas de formação: Serviço Social (seis), Enfermagem (nove), Farmácia (três), Odontologia (um), Psicologia (19), Psiquiatria (um), Terapia Ocupacional (14).

Foi sugerida a leitura do Guia do Moderador (2014), que propõe orientações ao mediador de grupo (seja profissional ou usuário), e não regras fechadas que universalizem a experiência com a GAM, como explicita o trecho abaixo:

As questões que aqui trataremos são fruto da nossa experiência. Não são todas as experiências possíveis no trabalho com o Guia GAM, pois muitas outras experiências irão surgir para você e para outros moderadores no transcurso do trabalho. Mas são ideias que também podem ajudar a encontrar seu jeito próprio de conduzir o grupo (Campos et al, 2014, p. 28).

O Guia do Moderador (Campos et al, 2014) discute o contexto do surgimento da GAM e os seus princípios e, em seguida, apresenta as etapas da formação dos grupos GAM, quais sejam: convite aos usuários; momento de contratação, em que seriam expostas as condições para o acontecimento dos encontros; e algumas diretrizes para dar início ao grupo e manejá-lo de forma cogestiva. Além disso, seis passos compõem as diretrizes para abordagem de cada seção do livro: a) "deixar as pessoas mais à vontade, e apoiá-las para que se conheçam e se aproximem, para quebrar o gelo" (p. 28); b) garantir "que cada participante possa fazer o exercício de se observar com relação a vários aspectos da sua vida. [sendo] a medicação um deles" (p. 29); c) propor "que os usuários identifiquem uma rede de apoio - pessoas, serviços e grupos", bem como a discussão "sobre os direitos e compromissos que cada um tem em relação ao seu tratamento" (p. 31-32); d) propor que o usuário "conheça mais sobre a sua própria experiência no uso de remédios e que se informe sobre o que é dito pela 'ciência', para comparar com aquilo que vive” (p. 34); e) revisar o Guia e retomar as discussões, "como uma forma de exercer a autonomia e aumentar a participação de cada um no seu tratamento" (p. 34); f) direcionar o processo para "identificar problemas e definir estratégias de ação para enfrentá-los" (p. 34-35).

O estabelecimento e a conceitualização dos princípios da GAM no guia do moderador direcio- 
nam para uma experiência flexível, porém, minimamente delimitada pelos enunciados de autonomia e cogestão. Desta forma, entenderemos estes e outros conceitos GAM neste trabalho por enunciados, por visarem muito mais do que descrições linguísticas, direcionando a construção de posturas éticas e políticas frente ao cuidado em saúde mental.

A pesquisa multicêntrica da qual se depreendeu o presente trabalho, se configurou como participante, do tipo apoio, proposta por Furlan e Campos (2014), criando-se um espaço em que os participantes são convidados a reunir-se em rodas de conversa para trocas e discussões sobre determinado tema. A pesquisa-apoio tem destaque no campo da Saúde Coletiva por meio da abordagem institucional Paideia, buscando condicionar um maior comprometimento, tanto dos usuários das instituições quanto dos profissionais e pesquisadores, no que diz respeito às suas posições e ao que fazem nos contextos de saúde, além de considerar os próprios pesquisadores como objetos de análise.

O pesquisador pode contribuir com seus conhecimentos ou pensamentos críticos a respeito dos assuntos abordados e facilitar a mobilização de estruturas já cristalizadas pelos profissionais e usuários dos serviços, além de fornecer o suporte técnico para o desenvolvimento dos encontros. Por meio de análises, investigações, discussões, reflexões e ações em conjunto, procura-se propiciar momentos que favoreçam a construção de maior autonomia aos envolvidos.

Os materiais das produções narrativas dos encontros e da leitura do guia GAM do usuário (Campos, Passos, Palombini, \& Serpa, 2012) e do moderador (Campos et al., 2014) foram analisados em termos de seus conteúdos discursivos. Foram selecionados, na leitura das transcrições e dos guias, trechos que correspondessem aos objetivos deste trabalho. Para isso, nas leituras das transcrições dos quatro primeiros encontros, as falas dos participantes e o conteúdo dos guias foram relacionados em suas confluências e dissonâncias e, posteriormente, algumas das práticas discursivas e não discursivas da estratégia GAM foram mapeadas. Depreenderam-se os seguintes vetores de análise: cidadania, conscientização, cogestão, autonomia e anormalidade/normalidade, com o intento de pensar a estratégia GAM como uma ferramenta de condução de sujeitos da saúde mental.
Para a análise dos materiais deste artigo, optou-se pela perspectiva arqueogenealógica de Michel Foucault, entendida pela busca atenta das discursividades e dos saberes que se constituem por meio de práticas. Os discursos são compostos por múltiplos enunciados passíveis de ligamentos, desligamentos ou transformações em seu caráter de verdade ao longo da história, podendo ser organizados de diferentes formas e, com isso, desencadeando diferentes sentidos para um mesmo discurso. Desta forma, pensar o saber enquanto uma prática inserida em uma linguagem que transpassa um regime de verdade, assegurado por determinado momento histórico é, portanto, pensar em um discurso. Ou seja, por meio do ato, da observação e do contexto fabricam-se saberes que se determinam entre verdadeiros e falsos dependendo das limitações e abrangências de certo tempo histórico.

Já pensar o poder - o qual é indissociável do saber, como todo ato, espaço e gesto - é pensá-lo não desprovido de significados, mas para além do domínio das palavras e, portanto, no campo das práticas não discursivas. Assim, quando um discurso passa a ser desconsiderado enquanto lugar de verdade $\mathrm{e}$ descartado, isso acontece devido à formação de resistências a saberes e poderes já naturalizados, possibilitando mudança e transitoriedade nas relações e, consequentemente, a admissão de novas ligações enunciativas para a constituição de diferentes discursos de verdade.

Para Dreyfus e Rabinow (1995), esta seria a experiência do arqueogenealogista: deter-se na constituição dos atos discursivos sérios de um determinado momento histórico, ou seja, as formações do que se torna verdadeiro com a possibilidade de execução de algum tipo de poder nas relações entre os sujeitos. $\mathrm{O}$ arqueogenealogista mapeia os enunciados de um discurso procurando suas ligações, suas confluências naturalizadas, perguntando-se: por que, em determinado momento histórico, um discurso foi composto por certos enunciados e não por outros? Para Foucault, para falar seriamente sobre um objeto, precisamos analisar "que tipos de coisas podem ser ditas seriamente sobre eles, quem pode dizê-las e que conceitos podem ser usados ao dizê-las" (p.79). Assim, entendemos que o discursivo e o não discursivo não se encontram em identidades singulares e, posteriormente, em justaposição, e sim em articulação, visto 
que estas práticas não são possíveis de maneira dissociada (Candiotto, 2013).

Neste sentido, explanaremos, primeiramente, no que implica a relação dos pesquisadores com o seu campo de pesquisa enquanto lugar de resistência a uma lógica disciplinar. Depois, discutiremos acerca do posicionamento dos profissionais, sustentados pela estratégia GAM, em relação ao sujeito da saúde mental. Acompanharemos os enunciados de normalidade/anormalidade em relação às práticas de conscientização e de 'fazer ouvir e falar' produzidas pela GAM. Finalizando com uma reflexão sobre os princípios GAM de autonomia e cogestão relacionados à cidadania biológica.

\section{O cenário circunscrito pelos pesquisadores GAM}

A proposta de reunir profissionais, usuários, acadêmicos e interessados na troca de experiência GAM acontece em uma Universidade, lugar de produção de conhecimento, de estabelecimento e desconstrução de verdades, de formação de sujeitos e, entretanto, de restrito acesso à população em geral. Essa longa e seletiva escalada do processo educativo para aceder ao ensino, denominado superior, posicionava os professores-pesquisadores como aqueles que capacitariam os interessados. Cientes de que esta relação vertical não fazia parte daquilo que se primava na pesquisa e tampouco na proposta dos grupos GAM, procurou-se refazer o ambiente e as relações entre os envolvidos.

Nos preparávamos, pesquisadores, para estar com uma certa antecedência no local dos encontros, não somente para aguardar a chegada dos convidados, mas para recompor a sala espaçosa da universidade. Desfazíamos o cenário de uma típica sala de aula tradicional, com classes e cadeiras enfileiradas, onde ficam os alunos ajustados, direcionadas a um quadro-negro - suposto lugar do professor, da autoridade, da verdade a ser transmitida -, para constituir outra ordem, outro movimento formado por um grande círculo de cadeiras no centro da sala. No meio da roda, uma térmica de chá e outra de café, biscoitos, bolos e um gravador. Todos podiam se encarar, as classes não estavam mais na frente dos corpos, o quadro-negro, praticamente invisível, inutilizava-se, e nós, pesquisadores, abríamos os diálogos: uma proposta mais ou menos constituída na não imposição dos debates. Um espaço de suposta livre participação, questionamentos e exposição de ideias, sem a preocupação com o certo e o errado, com os julgamentos e, principalmente, com a promessa de que os pesquisadores não estariam ali para orientações sobre o uso do guia. Com isso, procurava-se não conferir a postura ideal de um moderador ou a maneira como os grupos GAM deveriam funcionar.

O discurso dos pesquisadores e a sua aparente opacidade nas rodas de conversa tinham por intuito incitar os participantes a produzir saberes sobre suas experiências e a se responsabilizar por fazer circular a palavra. Isso os levava a romper com a lógica tradicional, que dita que deveriam organizar suas experiências de acordo com os saberes dos pesquisadores. Esta hipotética "liberdade" de expressão estava inserida em um jogo de saber e poder, que, na ausência da figura que transmite o conhecimento sobre o assunto, colocava a necessidade de entrar ao menos minimamente em contato com a leitura e apropriação dos guias e princípios da GAM. Assim, percebemos a sutileza da relação estabelecida, em que uma espécie de autonomia oportunizou que os participantes se tornassem protagonistas dos grupos. Eles foram estimulados a exportar suas emoções, reflexões, aflições, dúvidas, ideias, sugestões e críticas para dentro deste espaço - um campo de forças preparado para trocas e domínio de pesquisa.

Estabeleceram-se, portanto, algumas das disposições para a implementação dos grupos GAM nos serviços de saúde: criar um lugar de fala aos sujeitos da saúde mental que não teriam esta possibilidade; fazer circular saberes necessários para uma conformação aos conceitos GAM que possibilitarão a alteração das relações do usuário com os serviços de saúde; e informar direitos e deveres aos usuários acerca de sua cidadania para que eles busquem conquistá-los.

Essas circunstâncias inseriram todos em uma lógica de saber e poder similar à que a estratégia GAM pretende que se implemente e se modere nos serviços de saúde. É nesse campo de negociação que um dos pesquisadores exprime:

O espaço aqui é realmente esse de troca de experiências. E que a forma de qualificar o uso do guia é a partir da experiência de cada um. Por isso, então, nós acordamos isso no primeiro encontro e vamos seguir dentro dessa ideia de tentar qualificar esses encontros a partir muito mais da experiência, do que alguém que vai externa- 
mente conceituar, definir como, o que é o Guia, né. É a partir, realmente, desse encontro aqui e das conversas, que o que passar aqui por esse grupo, né, pelas afetações que passarem por esse grupo aqui, é que nós vamos construindo essa maneira de fazer o trabalho com esse dispositivo, com essa ferramenta que é o guia GAM.

O jogo enunciativo que se exprime desvia a ordenação do grupo do lugar de concepção originária e universalista de verdade, característico do pensamento ocidental moderno, o qual nos impõe que, para chegarmos a ela, necessitamos de instrumentos, categorias e linguagem apropriados para sua legitimação (Candiotto, 2007). Assim, a função pesquisador tentava resistir a uma certa condição pedagógica disciplinadora, da docilidade e utilidade dos corpos, para constituir o grupo por meio da estratégia GAM. Ao mesmo tempo, adotava outra forma de condução quando se posicionava frente ao grupo por uma espécie de "não saber", uma aceitação por não transmitir verdades sobre o tema GAM - mesmo que existam tais concepções -, o que possibilitava que os integrantes criassem seus conhecimentos sobre o uso do guia, essencialmente, pela troca de experiências.

Esse tipo de condução pode ser pensado por meio do que constitui "experiência" e "liberdade" a partir do pensamento foucaultiano. A liberdade estaria muito mais ligada ao território do limitado do que ao do irrestrito e absoluto, como, por vezes, nos levamos a acreditar. O limite surge juntamente à necessidade de liberdade, ou seja, ela é exercida apenas quando possuímos delimitações no espaço. Desta forma, não negamos que as vivências do sujeito frente à vida tenham uma relação subjetiva com ele mesmo, porém, elas só podem se concretizar enquanto experiência na medida em que o que se viveu é passível de ser comunicado e validado e, portanto, passar por delimitações sociais. Portanto, uma vivência não ganharia o status de experiência subjetiva se não fosse, em algum momento, ou em certa medida, passível de ser esbarrada pelas concepções de outrem (Sampaio, 2011).

A liberdade, nos encontros de roda de conversa, ocorria na medida em que, ao expressar suas vontades, práticas, pensamentos etc., esses sujeitos entravam em contato com as delimitações exercidas pelo grupo. Ao sofrer este impacto, as ideias ganhavam um tom cabível na experiência não só do sujeito que conta, mas também do que ouve, ganhando um status do que pôde ser dito naquele momento, com aquelas e sobre determinadas pessoas. Assim, a legitimidade daquilo que os profissionais e os usuários faziam em seus grupos GAM se confirma por meio dos relatos da memória de suas ações e das dissidências e confluências destas narrativas (Campos, 2011).

Com isso, queremos dizer que a liberdade não é algo possível na ausência de relações de poder, pelo contrário, ela se faz existir no exercício do poder. $\mathrm{E}$ é no campo móvel dessas forças que fazemos nossas escolhas éticas e políticas em uma atividade de defesa ou também de afirmação de si e dos outros. Indivíduos e coletivos exercem sua liberdade no campo histórico de possibilidades disponíveis para que suas ações, condutas e comportamentos possam acontecer. No contexto desta pesquisa, poderemos visualizar a formação de práticas e discursos que abrem um campo distinto de organização das relações de saber e poder e em disputa aos modos de intervenção sobre a figura do doente mental no âmbito médico psiquiátrico criticados pela Reforma Psiquiátrica Brasileira.

\section{Forjando o sujeito histórico crítico da saúde mental}

O guia GAM (Campos et al, 2012; 2014) se denomina estratégia, ou seja, tem suas regras, pretende um alvo, um modo de condução de sujeitos. Quer dizer, por mais que os moderadores dos grupos amparem "as experiências mais diversas", criem "um ambiente de confiança e abertura", ajudando "cada participante a se sentir à vontade no próprio grupo", isto se faz "para negociar o seu tratamento e torná-lo mais afinado à sua própria situação de vida" (Campos et al, 2014, p. 8). Com relação a essa forma peculiar de governo da vida, que acolhe as experiências a fim de direcioná-las ao protagonismo do tratamento, pode se encontrar indícios no guia do moderador GAM. Como se lê no início do material, com uma proposta de enfrentamento sobre o problema da forte dependência das práticas de saúde mental aos psicofármacos,

A GAM busca que as pessoas que usam psicofármacos sejam mais críticas com o uso que fazem deles, que conheçam melhor os medicamentos que usam cotidianamente e seus efeitos desejados e não desejados. Busca, ainda, que conheçam 
quais são seus direitos e que saibam que podem decidir se aceitam ou recusam as diferentes propostas de tratamento. Assim, dois princípios importantes da GAM são: o direito à informação e o direito a aceitar ou recusar os tratamentos. Para a GAM, a participação das pessoas nas decisões sobre os seus tratamentos é algo central (Campos et al, 2014, p. 05).

Denota-se uma estratégia que pretende forjar uma posição discursiva de sujeito capaz de mais crítica, de mais conhecimento, de poder de decisão e participação sobre o seu tratamento. “[U]ma estratégia pela qual aprendemos a cuidar do uso dos medicamentos, [...] aumentar o poder de negociação desse usuário com os profissionais da saúde [...], considerar a experiência prévia do usuário" (p. 07). Ou seja, a aprendizagem não está na aceitação e cumprimento incondicional daquilo que quem prescreve o medicamento demanda. Pelo contrário, ao considerar as repercussões do psicofármaco em sua vida, sono, potência sexual, apetite, diagnósticos, preconceitos, relação com cuidadores, entre tantas outras, o usuário deve adentrar o espaço da consulta psiquiátrica - onde antes se acomodava em sua suposta ignorância sobre si com sua doença em uma relação médico e paciente - para negociar a maneira como vai lidar com sua circunstância psiquiátrica, posto que passa a saber falar sobre si e escolher o que deseja para sua vida, em uma relação médico e usuário cidadão.

Interessante apontar que o guia pede aos moderadores GAM que pratiquem esta estratégia "[...] de forma coletiva, em grupo, de maneira dialogada e compartilhada" (p. 08), justamente porque o que se busca não é um espaço de tratamento, mas de conversa e problematização sobre essa terapêutica e de potencialização da autonomia do usuário. Os moderadores são aconselhados a não serem rígidos quanto ao uso do guia, pois "[o] que importa, afinal, para avançar e aprofundar o GAM, é incorporar e viver na prática os princípios e valores que orientam a Gestão Autônoma da Medicação" (p. 09). Assim, percebe-se que aquele que passa a participar de um grupo GAM é convidado a exercer um estilo de vida, é inserido em uma ética consigo e com os outros, para “[...] propiciar o questionamento e a crítica do óbvio, das 'verdades' que se consideram 'naturais' e que são construídas historicamente, servindo a interesses específicos" (p. 23).

O que se percebe é que a GAM, de certa maneira, valida e defende a autonomia e a cogestão de indivíduos e coletivos da saúde mental - princípios que abordaremos mais adiante -, por meio da herança das teorias e movimentos críticos que questionaram o campo da loucura, da doença mental e dos manicômios em nossa sociedade, problematizando as ditas verdades da medicina psiquiátrica e das formas de tratamento, bem como os modos sociais de compreensão da loucura. Esse espaço crítico torna-se também espaço de ação política para as intervenções da GAM, que, por meio das experiências compartilhadas em grupo, elabora a construção discursiva de uma posição de sujeito da saúde mental engajado histórica e criticamente.

Assim, pode-se pensar que aqueles que participaram dos encontros e que entraram em contato com o guia GAM foram atravessados em suas práticas por enunciados, como direitos, participação, cidadania, autonomia, cogestão, entre outros. Eles passam a fazer parte do estatuto do sujeito da saúde mental devido às condições geradas pelo advento da Reforma Psiquiátrica. É desta forma que os participantes das rodas de conversa entram em um circuito estratégico que possibilita que a GAM funcione nos serviços de saúde da região mencionada.

\section{A conscientização para a inserção do anormal na normalidade}

As análises das narrativas desses profissionais/ participantes demonstram a lógica das rodas de conversa, no viés dos seus locais de trabalho. Em seus serviços, eles tentam resistir a uma forma de assujeitamento do usuário frente a um saber médico, ao mesmo tempo em que produzem novas formas de conduzir essa relação:

Independentemente de tomarem ou não tomarem medicação é importante que eles se conscientizem que são seres humanos, que são pessoas, eles têm que se valorizar, eles têm que se conscientizar que são importantes como qualquer um de nós, qualquer outra pessoa considerada normal (Fala de um Profissional). 
Nesse excerto, é possível pensar que o profissional estaria dizendo ao usuário: "mesmo se você fizer uso de uma medicação psiquiátrica, que supostamente o tornaria normal, você precisa saber que você não é a doença. É um ser humano do qual talvez você não tenha mais consciência e, por causa disso, você precisa se considerar importante mesmo tendo se tornado, pela sua doença mental, anormal”. Há uma insistência em deslocar o lugar da doença mental, considerando-a uma entre tantas outras dimensões do ser humano, e em permitir e validar ao usuário da loucura percorrer enunciados pertencentes ao discurso da normalidade.

O guia do Moderador (Campos et al, 2014), sugerimos, vai na mesma esteira discursiva, quando se encontram usuários que se apresentam por meio de seus diagnósticos: “[e]sse momento é valioso, porque podemos ampliar a conversa, salientando que somos todos pessoas, para além de qualquer transtorno mental" (p. 29). Desta forma, o discurso da GAM desqualifica a doença enquanto identidade do sujeito da saúde mental e requalifica a sua condição de pessoa, por meio da conscientização e do alargamento da conversação.

Assim, gostaríamos de situar esta análise na passagem histórica de um discurso dicotômico - que colocava, de um lado, aqueles considerados conscientes de si mesmos e, de outro, aqueles incapazes disso - para um discurso inclusivo da loucura. Este discurso dicotômico aflora no século XVIII, com a formação de um sujeito do Iluminismo, baseado na noção de indivíduo centrado, com capacidades de razão, de consciência e ação, em uma interioridade que assegurava sua identidade permanente enquanto pessoa humana. Veremos que nesse processo de passagem discursiva a categoria consciência é central para definir o humano, mesmo que venha sendo ressignificada contemporaneamente. Ou seja, ainda que seja louca (portadora de sofrimento psíquico), a pessoa pode se conscientizar de sua humanidade e de sua cidadania.

Neste sentido, se a loucura é um estado de desrazão, ou seja, um estado no qual o sujeito não sabe o que faz, passa a ser fundamental que o usuário produza algum tipo de "consciência" sobre sua doença, pois é através desta que ele ocupará espaços no campo da normalidade. O termo "consciência" é utilizado aqui de acordo com o sentido atribuído nos discursos dos profissionais nas rodas de conversa, em confluência com os termos informação e orientação. Isso ganha visibilidade quando uma profissional diz que "esses sujeitos que vão até as unidades, que participam do guia, eles se autorreavaliam sobre a questão do uso da sua medicação. Conseguem um momento no qual eles são mais esclarecidos, organizados e orientados", bem como no comentário de um profissional sobre os efeitos da GAM na relação com as medicações:

As pessoas por não lerem, por estarem desinformadas sobre o que usam, que medicamentos eles estão usando e quais os efeitos que eles vão causar, é que acontece, muitas vezes, o abandono, né. A pessoa vai abandonar aquele tratamento, porque acha que é só com ele que tá acontecendo aquele problema e não. Tá acontecendo no geral. Às vezes, se há uma orientação [que em] determinado tempo esses efeitos vão diminuindo ou teu organismo vai se acostumando... Então, quer dizer, a pessoa vai se sentindo mais tranquila, mais segura (Fala de um profissional).

Assim, se no discurso da saúde mental passaram a percorrer enunciados de conscientização, como forma de informação, orientação e atribuição de um poder ao objeto desse discurso, que são os usuários, então se organiza uma linguagem capaz de produzir um tipo de agenciamento sobre esses sujeitos. Ao transmitir determinadas informações aos usuários, o nível da linguagem é ultrapassado, e surgem novas formas de relação com eles mesmos e com o mundo. Conforme um psicólogo da residência multiprofissional em saúde mental, "Num primeiro momento foi difícil explicar para os usuários que o grupo não era um grupo sobre medicação, né. É um grupo pra falar, é pra falar sobre a experiência de tratamento [...] de como eles se posicionam frente ao saber do médico". Desqualifica-se a ideia do usuário de saúde mental alienado, distante da sociedade e desprovido de direitos políticos. Em contrapartida, qualifica-se o mesmo, através da "conscientização", para tomar conhecimento sobre a sua doença e o seu tratamento e incluir-se na sociedade através da sua condição de cidadão.

[...] as pessoas, a maioria desconhece os seus direitos como usuários também. Até não é uma 
questão de médico e paciente, eu acho que é uma questão do paciente estar consciente em relação ao tratamento em que ele está sendo colocado. [...] se ele não está contente, não está satisfeito com aquele profissional, psicólogo, psiquiatra, [...] ele tem o direito de procurar aquele que ele tiver mais né, afinidade [...] (Fala de um profissional).

Não necessariamente se quer transformar o sujeito louco em sujeito normal, mas incluir a sua anormalidade dentro do que é normal em nossa sociedade.

Não! Não tem nada a ver com loucura. Eu acho, simplesmente, isso aí é um preconceito, um tabu que tem que ser vencido por nós profissionais, de chegar ao ponto de dizer, não, realmente, eu tô precisando de ajuda. O meu grau de loucura, às vezes, muitas vezes, pode ser considerado o padrão normal, pode ser muito maior que do que qualquer um que tá com o transtorno, seja lá o que for (Fala de um profissional).

Norma, para Foucault (1984), seria todos os dispositivos que buscam medir e classificar sujeitos de acordo com padrões. A escola, o hospital, as instituições, a prisão e os manicômios, por exemplo, estão a serviço da norma, seja para detectar a anormalidade, seja para corrigi-la. Em uma sociedade conduzida pela lógica do biopoder, o Estado busca cada vez mais agir sobre a população de forma a alcançar a sua regularidade, enquadrando-a no espectro arbitrário da normalidade. O médico, a medicalização, a confissão, o tratamento e o Centro de Atenção Psicossocial (CAPS) fazem parte do circuito estratégico que busca possibilitar algum aparato a esse sujeito que não mais pode ser excluído e internado em instituições psiquiátricas por tempo indeterminado, como ocorria na lógica manicomial, por exemplo.

Desta forma, a GAM entra como um instrumento de resistência às condições de possibilidades históricas da existência da loucura em nossa sociedade, buscando remodelar a relação do usuário com a doença, com seu médico, com seu tratamento, com o espaço da saúde mental e, principalmente, com a sua condição de cidadão perante a sociedade, em um reposicionamento da figura do usuário frente às relações de saber e poder que circundam sua anormalidade.

\section{A vida anormal ouvida e falada no espectro da normalidade}

No trecho exposto abaixo, visualizamos a repetição da tentativa de inserção do usuário da saúde mental em uma modalidade enunciativa que possibilite-o um status de normalidade dentro de um discurso do anormal. A autoridade que avalia o doente mental (o médico, o enfermeiro, o psicólogo etc.) passa a reconhecer todos os âmbitos da sua vida como importantes. Assim, o usuário circula por um discurso de normalidade na medida em que se reconhece que uma parcela das suas vivências, passíveis de ocorrer na vida das pessoas "normais" em graus de intensidade diferentes, pode estar relacionada à sua condição de anormalidade. Os profissionais são expressão da gama discursiva da GAM ao vivenciar, na prática, os grupos enquanto ferramenta que agencia um campo de possibilidades no qual o sujeito da saúde mental pode falar sobre a sua vida.

Eles vêm com questões né, eles querem trazer questões sobre medicação, eles querem trazer coisas que aconteceram na própria vida, porque eu sempre falo assim pra eles "bom, não adianta tomar o medicamento bem direitinho, nos horários certos, só isso não vai te segurar né. Tem toda uma questão emocional por trás e aqui é um espaço pra vocês falarem sobre isso né". Então eles trazem muito sobre a vida deles, porque eles sabem que tem situações diárias que acontecem que desestabilizam, por mais que eles estejam tomando o medicamento da forma mais correta possível (Fala de um residente).

Percebe-se que ao passo em que o grupo direciona ao processo medicamentoso - organização com diagnóstico e tratamento psiquiátrico -, ele também é um espaço do direito de falar sobre as experiências de vida carregadas de emoção, que podem estar para além do que seria visível pela doença, não permitindo seu retorno. Falar sobre o cotidiano e suas vicissitudes seria, de certa maneira, um tratamento desviado do foco da doença. Seria preciso entender a doença apenas como uma das múltiplas dimensões da vida do sujeito, abarcando as diversas vivências dos usuários enquanto condições humanas possíveis e, assim, normais de vida.

Ao pensarmos nessa variedade de dimensões de experiências de vida que o sujeito da saúde men- 
tal pode agora exprimir, é possível fazer uma analogia com o que Foucault (1973-1974/2006) abordou sobre a prática da confissão, que, para ele, havia se tornado uma estratégia de disciplina fundamental para o exercício do poder psiquiátrico. Assim, ela ganhou status de terapia porque ao confessar algo sobre si o sujeito amarrava-se ao que contava sobre a sua história, assumindo uma queixa, um discurso e um posicionamento em torno da sua doença. Porém, percebe-se em nossa análise que estes espaços GAM que incitam a troca de experiências em todas as suas dimensões não obedecem à mesma lógica da confissão daquela época. É evidente que há uma continuidade histórica no que diz respeito às práticas confessionais no campo da psiquiatria, mas, em meados do século XIX, elas funcionavam como estratégia para pôr um fim à loucura. Desejava-se que o sujeito, em seu estado de desrazão, assumisse um discurso que o possibilitasse acreditar que era louco, para, em seguida, descaracterizar aquilo que lhe dava condições para afixar-se em sua loucura e ser reconhecido enquanto tal.

Na GAM, percebe-se que a confissão da vida do doente assume uma ótica que se difere da anterior, pois objetiva, por meio da necessidade do compartilhamento da experiência, a diluição, a relativização e a potencialização da doença. A doença é diluída no sentido de ser uma entre as várias condições de existência do sujeito, considerando que o sofrimento e a desestabilização estão presentes no cotidiano; relativizada pela variação das perspectivas de normalidade e anormalidade conforme contexto de vida, condição social, relações institucionais, crítica à sociedade etc.; e potencializada porque o diagnóstico torna-se uma estratégia para mudança social, conquista de direitos e exercício de cidadania.

Assim, a estratégia GAM configura-se nessa lógica de proporcionar ferramentas que produzam no sujeito da saúde mental um viés político de existência, tornando sua doença/vida objeto e corpo de lutas políticas.

[...] desde que a gente nasce já vêm padrões e sistemas que nos impõem certas condições, que tem que ser assim, tem que ser assado, tem que ser gordo, tem que ser magro, tem que ser branco, tem que ser preto, tem que ser rico, tem que ser pobre. Então aquela condição que nos limita. [...] porque o problema de tu olhar o paciente é uma coisa. E tu ouvir o que ele tem pra te dizer é dife- rente. E muita... a maior dificuldade nossa como profissional dentro dessa área é a gente ouvir o que que o paciente vai colocar pra gente (Fala de um profissional).

Assim, se hoje a vida é objeto de investimento por parte do Estado, o discurso desses sujeitos da saúde mental sofre uma grande mudança a respeito dos atos discursivos sérios. Agora é sério ouvir um usuário de saúde mental falar sobre seus direitos, medicamentos, sentimentos, produzindo um sentido para a sua desrazão, de modo a torná-la cada vez mais próxima da racionalidade e distante do delírio.

Nesse sentido, podemos pensar o quanto os discursos que atravessam os profissionais passam a materializar-se em um tipo de governo que visa apontar para o usuário os lugares que ele, agora, pode ocupar. Lugar de cidadão, de militante político, de protagonista no seu tratamento de saúde mental, de sujeito que reivindica, assim como cumpre direitos e deveres perante a vida em sociedade. Mais do que isso, é através das rodas de conversa que esse profissional sustenta o lugar de militante GAM e, assim, proporciona aos usuários vislumbrarem outros lugares que eles não só podem, como devem ocupar.

\section{A cidadania da saúde mental pelos princípios de autonomia e cogestão}

Ao nos aproximarmos da conclusão de nosso trabalho, pontuamos que nossa intenção foi pensar, a partir do conceito de cidadania biológica, a estratégia GAM, que emerge em torno de um discurso de emancipação política do usuário de saúde mental, de maneira a resistir a uma lógica disciplinar e implantar um novo modo de condução dessas vidas. Desta forma, analisamos a GAM, buscando mostrar suas estratégias de governo e estabelecimento de verdades no que diz respeito às formas de entendimento e produção do sujeito da saúde mental que possibilitam que ele exerça outros papéis, que vão além da sua condição psiquiátrica.

Para a GAM (Campos et al., 2014), "os usuários devem ser considerados protagonistas e corresponsáveis (responsáveis junto com os profissionais) pelo tratamento que seguem. Eles devem ser considerados capazes de compartilhar as decisões sobre o próprio tratamento, inclusive sobre o uso de seus medicamentos". Sendo assim "as pessoas têm que compartilhar, umas com as outras, o que pensam e o que sentem, ao 
invés de se fecharem em suas ideias e posições". "Por isso, quando falamos de gestão autônoma, não estamos falando de uma gestão independente da própria vida do usuário, mas de uma cogestão" (p. 9-10).

Estes apontamentos delineiam o desmantelamento e a reconstrução de relações entre saber e poder que circundam o nosso objeto de análise - o sujeito biológico e cidadão da saúde mental. Isso diz respeito à possibilidade deste sujeito entrar no campo enunciativo da normalidade, apesar da sua anormalidade, e a partir dela. Os enunciados de autonomia e cogestão, centrais para os princípios da GAM, tornaram-se passíveis de conexão com o discurso do sujeito da saúde mental e estão acarretando, em nossas análises, uma transformação prática na desenvoltura desses usuários. Estes enunciados passam a constituir na experiência destes sujeitos deveres e direitos, características constituintes do discurso do cidadão político. Essa arena da autonomia tem, a partir da GAM, o significado avesso do "ser independente e suficiente". Isso decorre justamente porque, agora, estes sujeitos da saúde mental, além de serem instigados a sair da posição passiva de 'paciente", exercendo maior controle sob suas vidas, precisam adquirir posturas participativas na sociedade. Ou seja, esse sujeito forjado da saúde mental é colocado em um campo onde, para ter o direito de existir enquanto cidadão biológico e político, deve percorrer algumas práticas que o possibilitem tal status/condição. Isto fica claro, pois, segundo a GAM (Campos et al, 2014), autonomia, é sempre construída na relação com o outro, em um exercício de compartilhamento de diferentes pontos de vista, numa experiência de cogestão. Pensar em gestão autônoma de medicação implica considerar os usuários como protagonistas e corresponsáveis na gestão do tratamento com medicamentos, participando da decisão de usá-los e do modo como usá-los (p. 11).

As rodas de conversa construídas e analisadas neste trabalho objetivaram, ao nosso olhar, interesses políticos de governo da vida não só do usuário de saúde mental, mas também dos pesquisadores e profissionais que estabeleciam uma forma de se comportar perante uma estratégia ética de gestão dos corpos. A incorporação desta ética tem a ver com uma estética de vida em que almejamos tornarmo-nos iguais e assemelharmo-nos. Essa proximidade decorre da escolha de uma face discursiva que nos permite acreditar que estamos livres, mesmo estando delimitados a uma verdade e a um tipo específico de governo.

É possível inferir que, para Foucault (2003), a partir do século XVII a vida infame desses sujeitos malvistos, sem importância e de vida obscura ganham cada vez mais importância nos discursos políticos do Ocidente, passando do domínio de um monarca para os múltiplos domínios instaurados pela ciência, mais especificamente, da medicina, da psiquiatria e da Psicologia. Esses sujeitos devem fazer contato com um tipo de poder que os sustenta ao afirmarem a sua loucura e administrá-la. Assim, o doente mental ganha o estatuto de uma vida que merece ser contada, explorada e vista como importante.

\section{Referências}

Amarante, P. (2000). Loucos pela vida: A trajetória da reforma psiquiátrica no Brasil. Rio de Janeiro, RJ: Fiocruz.

Basaglia, F. (1985). A instituição negada. Rio de Janeiro, RJ: Graal.

Borkman, T. (1976). Experiential knowledge: A new concept for the analysis of self-help groups. Social Service Review, 50(3), 445-56.

Campos, R. T. O. (2011). Fale com eles! O trabalho interpretativo e a produção de consenso na pesquisa qualitativa em saúde: inovações a partir de desenhos participativos. Physis, 21(4):1269-1286. https://.doi.org/10.1590/ S0103-73312011000400006

Campos, R. T. O., Passos, E., Leal, E., Palombini, A. A., Serpa, O. et al. (2012). Guia da gestão autônoma da medicação - GAM. Campinas, SP: Unicamp.

Campos, R. T. O., Passos, E., Palombini, A. A., Gonçalves, L. L. M, Santos, D. V. D. Melo, S. S. J. et al. (2014). Gestão autônoma da medicação: Guia de apoio a moderadores. Campinas, SP: Unicamp. Recuperado de http://www. fcm.unicamp.br/fcm/laboratorio-saude-coletiva-e-saudemental-interfaces 
Candiotto, C. (2007). Verdade e diferença no pensamento de Michel Foucault. Kriterion, 48(115): 203-217. https:// doi.org/10.22409/rg.v14i2.626

Candiotto, C. (2013). Foucault e a crítica da verdade (2a ed., Coleção Estudos Foucaultianos). Belo Horizonte, MG: Autêntica.

Dreyfus, H., Rabinow, P. (1995). Michel Foucault: Uma trajetória filosófica (para além do estruturalismo e da hermenêutica). Rio de Janeiro, RJ: Forense Universitária.

Foucault, M. (2008). A arqueologia do saber (7a ed., L. F. B. Neves, trad.). Rio de Janeiro, RJ: Forense Universitária. (Original publicado em 1926).

Foucault, M. (1988). A história da sexualidade I: A vontade de saber. Rio de Janeiro, RJ: Graal.

Foucault, M. (1984). A história da sexualidade II: O uso dos prazeres. Rio de Janeiro, RJ: Graal.

Foucault, M. (2003). A vida dos homens infames. In: Foucault, M. Estratégia, poder-saber. Ditos e escritos IV (pp. 203222). Rio de Janeiro, RJ: Forense Universitária.

Foucault, M. (2006). O poder psiquiátrico: Curso Collège de France. São Paulo, SP: Martins Fontes. (Original publicado em 1973-1974).

Frossard, V. C, \& Dias, M. C. (2016). O impacto da internet na interação entre pacientes: novos cenários em saúde. Interface (Botucatu), 20(57): 349-361. https:// doi.org/10.1590/1807-57622014.1334

Furlan, P. G., \& Campos, G. W.(2014). Pesquisa-apoio: pesquisa participante e o método Paideia de apoio institucional. Interface (Botucatu), 18(1): 885-894. https://doi.org/10.1590/1807-57622013.0285

Hall, S. (2005). A identidade cultural da pós-modernidade (10a ed.). Rio de Janeiro, RJ: DP\&A.

Lei No 10.216, de 6 de abril de 2001. Dispõe sobre a proteção e os direitos das pessoas portadoras de transtornos mentais e redireciona o modelo assistencial em saúde mental.. Brasília, DF. Recuperado de: http://hpm.org.br/ wp-content/uploads/2014/09/lei-no-10.216-de-6-de-abril-de-2001.pdf

Rabeharisoa, V. (2008). Experience, knowledge and empowerment: the increasing role of patient organizations in staging, weighting and circulating experience and knowledge. In: Akrich, M., Nunes J., Paterson, F., Rabeharisoa, V. (eds.). The dynamics of patient organizations in Europe (pp. 13-34). Paris: Presses de l' École des Mines.

Rabinow, P. (1966). Artificiality and enlightenment: From sociobiology to biosociality. essays on the anthropology of reason. Princeton, N.J.: Princeton University Press.

Rose, N. (2013). A política da própria vida: Biomedicina, poder e subjetividade no século XXI. São Paulo, SP: Paullus.

Sampaio, S. S. (2011). A liberdade como condição das relações de poder em Foucault. Revista Kátalysis, 14(2): 222-229. https://doi.org/10.1590/S1414-49802011000200009

Tenório, F. (2002). A reforma psiquiátrica brasileira, da década de 1980 aos dias atuais: histórias e conceitos. História, Ciências, Saúde, 9(1): 25-59.

\section{Vitória Rosa Cougo}

Graduanda em Psicologia pela Universidade Franciscana - UFN-RS.

E-mail: vitoriapsico13@yahoo.com.br

Marcos Adegas de Azambuja

Professor Adjunto do Programa de Pós Graduação em Psicologia da UFSM

E-mail: marcos.azambuja@ufsm.br

Endereço para envio de correspondência

PPG Psicologia UFSM - Av. Roraima no 1000

Cidade Universitária, Bairro Camobi, Santa Maria - RS, CEP: 97105-900 
Recebido 05/04/2017

Reformulado 21/12/2017

Aprovado 16/01/2018

Received $04 / 05 / 2017$

Reformulated $12 / 21 / 2017$

Approved 01/16/2018

Recibido 05/04/2017

Reformulado 21/12/2017

Aceptado 16/01/2018

Como citar: Cougo, V. R., \& Azambuja, M. A. (2018). A Estratégia Gestão Autônoma da Medicação e a inserção da (a)normalidade no discurso da cidadania. Psicologia: Ciência e Profissão, 38(4), 622-635. https://doi.org/10.1590/1982-3703001072017

How to cite: Cougo, V. R., \& Azambuja, M. A. (2018). Autonomous Medication Management Strategy and the introduction of (ab)normalities in the discourse of citizenship. Psicologia: Ciência e Profissão, 38(4), 622-635. https://doi.org/10.1590/1982-3703001072017

Cómo citar: Cougo, V. R., \& Azambuja, M. A. (2018). La Estrategia Gestión Autónoma de la Medicación y la inserción de la (a)normalidad en el discurso de la ciudadanía. Psicologia: Ciência e Profissão, 38(4), 622-635. https://doi.org/10.1590/1982-3703001072017 


\section{ERRATA}

Na edição 38.4, http://dx.doi.org/10.1590/1982-3703001072017, no artigo "A Estratégia Gestão Autônoma da Medicação e a Inserção da (A)normalidade no Discurso da Cidadania", na página 623, primeiro parágrafo, linhas 2 e 3, onde se lê "(título retirado para evitar identificação dos autores).”, o correto é: “(Implementação e descentralização da estratégia da gestão autônoma da medicação (GAM) no estado do RS: efeitos de disseminação).” 